\title{
A Computer Program (COMPOST) for Predicting Mass Spectrometric Information from Known Amino Acid Sequences
}

\author{
I.A. Papayannopoulos and K. Biemann \\ Department of Chemistry, Massachusetts Institute of Technology, Cambridge, Massachusetts, USA
}

\begin{abstract}
A computer program (COMPOST) is described that carries out predictive computations on known amino acid sequences. The program is designed to be of use to mass spectrometrists with an interest in protein and peptide sequencing. Mass values (monoisotopic and average) for protonated peptide and protein molecules and elemental compositions are calculated. COMPOST also calculates mass to charge ratio values for protonated peptides expected from specified digests, locates specified amino acid subsequences or peptides of a specified molecular weight within a longer sequence, and predicts mass to charge ratio values for fragment ions from high-energy collision-induced dissociation of protonated peptides. (J Am Soc Mass Spectrom 1991, 2, 174-177)
\end{abstract}

$\mathrm{I}^{\mathrm{n}}$ $n$ the course of our work in the sequence determination of peptides and proteins by fast atom bombardment (FAB) and collision-induced dissociation (CID) mass spectrometry, we have developed computer programs to assist in the prediction and interpretation $[1,2]$ of FAB and CID mass spectral data. We wish to describe a useful FORTRAN program that carries out predictive computations on known amino acid sequences.

Program COMPOST (Computations On Modified Proteins Or Segments Thereof) is a program that accepts an amino acid sequence as input and provides information about and performs operations on that sequence, which are selected by the user from an options list (Figure 1). Some of the operations performed by the program are also available via remote access of databases. However, the package described here is directed mainly towards mass spectrometrists with an interest in protein sequencing. The development of a program with similar features has also been reported from another laboratory [3].

The amino acid sequence (single letter code, up to 3000 long) may be entered by the user at runtime or retrieved from a file (in the former case a file with the sequence thus entered may be created). The user may select to work on only part of the input sequence. The program recognizes the letters for the 20 common protein amino acids and $\boldsymbol{O}$ for ornithine as well as $\mathbf{X}$ if leucine and isoleucine are to be treated equal. The remaining four letters ( $B, J, U, Z$ ) may be used to designate uncommon amino acids, in which case the program requests the elemental composition for each such amino acid. COMPOST assumes that all amino

Address reprint requests to Klaus Biemann, Department of Chemistry, Massachusetts Institute of Technology, Cambridge, MA 02139. acid residues have the form -NH-CHR $-\mathrm{CO}-\left(\mathrm{R}_{\mathrm{i}}\right.$ is the side chain of the $i$ th amino acid; for proline $(\mathrm{P})$, $\mathbf{R}=\mathrm{C}_{3} \mathrm{H}_{5}$ ), and, in the case of uncommon amino acids, the composition of the side chain $R$ is to be defined; this has no effect on any operations except in predicting CID combined with mass spectrometry fragment ions (option 6 in Figure 1) for those cases where the modification is not restricted to the side chain but includes a substituent on the $\alpha$ nitrogen. For example, a decapeptide where the fourth amino acid is methylated at the $\alpha$ nitrogen $\left[-\mathrm{N}\left(\mathrm{CH}_{3}\right)-\mathrm{CHR}_{4}-\mathrm{CO}-\right]$ will have the masses of all its sequence ions correctly predicted except for $c_{3}$ (14 $\mathfrak{u}$ too high) and $\mathrm{z}_{6}$ (14 $\mathrm{u}$ too low). While this particular case could be incorporated into the algorithm, it is sufficiently rare to make it easier to simply make the correction. Modifications to any amino acids in the sequence entered may be either selected from a list of commonly encountered groups (phosphate, sulfate, glycosylation, peptide synthesis side-chain protecting groups, etc.) or defined; when such an amino acid occurs more than once, the program prompts the user to specify the position(s) of the modified residue(s). Modifications to the $\mathrm{N}$-terminus and/or the C-terminus may be specified in a similar manner. The program sets up a matrix of ten elements $(C, H$, $\mathrm{N}, \mathrm{O}, \mathrm{S}, \mathrm{P}, \mathrm{F}, \mathrm{Cl}, \mathrm{Br}, \mathrm{I})$ for every amino acid in the sequence; default values for the common or userspecified values for uncommon and/or modified amino acids are assigned prior to any computations.

The oxidation state of cysteines and any modifications thereof may be specified. If there are disulfides present, the user may specify the pairs of cysteines thus linked, if these are known. These linkages are taken into account when the expected peptides from a specified enzymatic or chemical digest are determined (option 7 in Figure 1). COMPOST contains provisions 


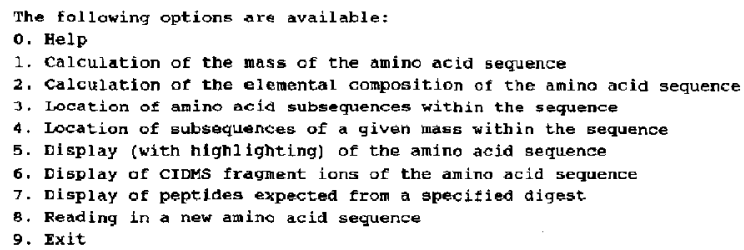

Figure 1. Options list displayed by the program after an amino acid sequence has been entered.

for cases where only some of the cysteines are involved in disulfide bonds while the remaining may be reduced or otherwise modified.

Once the amino acid sequence has been entered and any modifications to it have been specified, the program creates internally a table of the elemental composition of each amino acid present. All mass computations for peptides are carried out by summing the products of the atomic weight and the number of occurrences of each element in the amino acid residue, and adding the elements of water (unless a modification to the $\mathrm{N}$ - and/or $\mathrm{C}$-terminus has been specified). Monoisotopic $\left({ }^{12} \mathrm{C}\right)$ and average ("chemical") masses ${ }^{1}$ are calculated and double precision arithmetic is used for all noninteger computations. These values, for the neutral as well as the protonated molecule, are obtained by selecting option 1 from Figure 1. Option 1 also allows the user to select a portion of the amino acid sequence and then add or subtract amino acids from either terminus in a stepwise fashion and obtain the masses of the peptides thus defined. This is useful when searching for peptides derived from a posttranslationally truncated protein. Option 2 provides the elemental composition of the amino acid sequence.

A list of specific, commonly used enzymes or chemical cleavage methods is available in option 7 (Figure 2), and the predicted peptides from their activity on a known amino acid sequence may be obtained (Figure 3). COMPOST accommodates infrequently

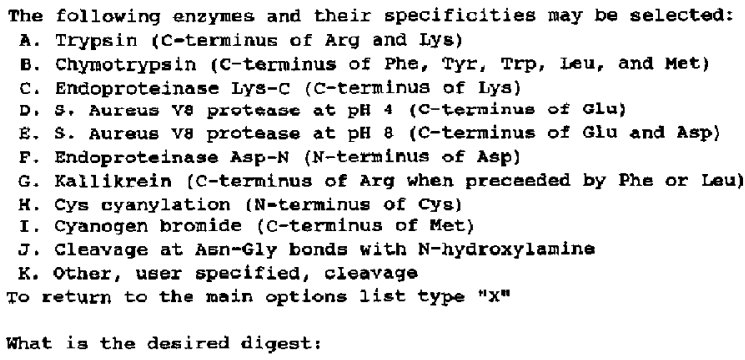

Figure 2. List of enzyme and chemical cleavage specificities (option 7).

\footnotetext{
${ }^{1}$ The monoisotopic and average mass values for the elements used in COMPOST were taken from refs 4 and 5 , respectively.
}

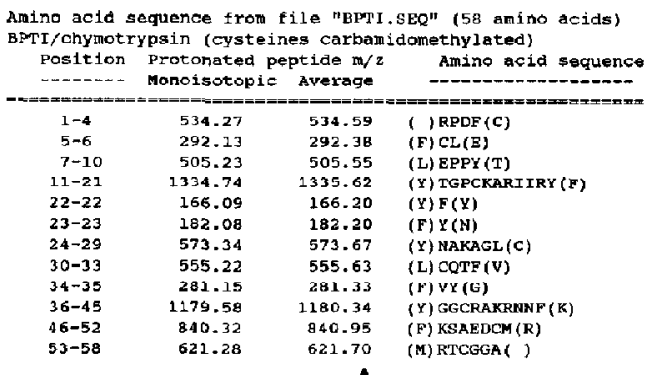

Amino acid scquence from tile "BPTI.SEQ" (58 amino acids) (1)

\begin{tabular}{|c|c|c|c|}
\hline Position & $\begin{array}{l}\text { Protonated p } \\
\text { Monoisotopic }\end{array}$ & $\begin{array}{l}\mathrm{ptide} \mathrm{m} / \mathrm{z} \\
\text { Average }\end{array}$ & Amino acid sequence \\
\hline $\begin{array}{l}1-4 \\
5-6\end{array}$ & $\begin{array}{l}534.27 \\
795.34\end{array}$ & $\begin{array}{l}534.59 \\
796.95\end{array}$ & () $R P D F(C)$ \\
\hline $53-58$ & & & (M) RTCGGA () \\
\hline $7-10$ & 505.23 & 505.53 & (L) EPPY(T) \\
\hline $\begin{array}{l}11-21 \\
36-45\end{array}$ & 3397.25 & 2398.83 & $\begin{array}{l}\text { (1) TG PCKARII I RY ( } F \text { ) } \\
\text { (Y) GGCRAKRNN } \text { ( } \mathrm{K} \text { ) }\end{array}$ \\
\hline $22-22$ & 166.09 & 166.20 & $(Y) F(Y)$ \\
\hline $23-23$ & 182.08 & 182.20 & (F) Y $\mathrm{Y}(\mathrm{N})$ \\
\hline $24-29$ & 573.34 & 573.67 & (Y) NAKACL (C) \\
\hline $90-33$ & 1278.48 & 1279.46 & (L) $\operatorname{CQTF}(v)$ \\
\hline $46-52$ & & & (F) $\operatorname{KSAEDCM}(R)$ \\
\hline $34-35$ & 282.15 & 281.33 & (F) $V Y(G)$ \\
\hline & & B & \\
\hline
\end{tabular}

Figure 3. Predicted peptides from a chymotryptic digest of bovine pancreatic trypsin inhibitor (BPTI, also known as aprotinin, 58 amino acids), with the cysteines either (a) reduced and carbamidomethylated or (b) linked by disulfide bonds (Cys ${ }^{5}$ $\mathrm{Cys}^{35}, \mathrm{Cys}^{14}-\mathrm{Cys}^{38,}$, and $\mathrm{Cys}^{30}-\mathrm{Cys}^{51}$ ). In parentheses are the amino acids immediately preceding or following the peptides to be expected. To save space a relatively small protein was chosen. The average protonated peptide molecule mass is calculated for the case of larger proteins and/or cleavage at infrequently occurring amino acids (e.g., at the C-terminus of Met with CNBr), which may give rise to peptides of high molecular weight that might be measured mass spectrometrically at less than unit mass resolution.

used enzymatic or chemical cleavages by allowing the user to specify cleavage at the $\mathrm{N}$ - or the $\mathrm{C}$-terminus of any amino acids or at the peptide bond between two specified amino acids. As mentioned above, if disulfide bonds are present and the pairs of cysteines thus linked are known, the predicted peptides from the

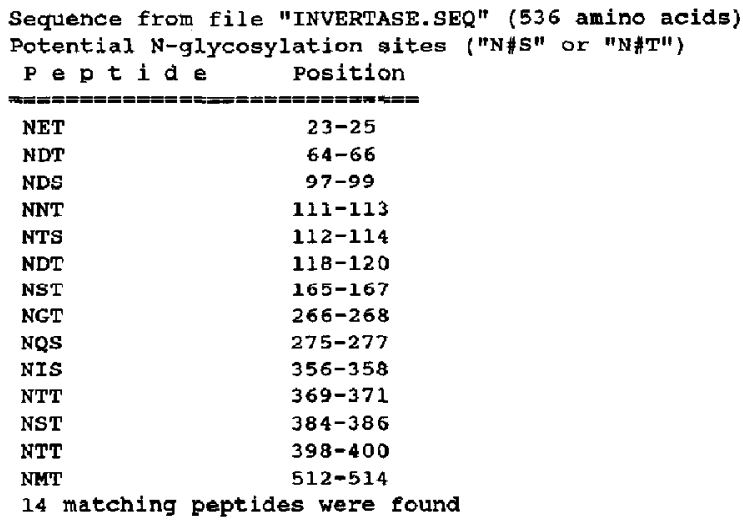

Figure 4. Potential N-glycosylation sites (" ... Asn-xxx-Ser..." or "...-Asn-xxx-Thr-...", where " $x x x "$ " may be any amino acid) of external invertase. 
Sequonce from file "BPTI. SEQ" (58 amino acide)
Cysteines rarbanidomethyiated

\begin{tabular}{|c|c|c|c|c|}
\hline \multirow{2}{*}{$\begin{array}{l}\text { FROTONATED } \\
\text { Entered } \\
\text { (average) }\end{array}$} & \multirow{2}{*}{$\begin{array}{c}\text { PEPTIDE HOLEC } \\
c \text { a } 1 \text { e u } \\
\text { (average) }\end{array}$} & \multirow{2}{*}{$\begin{array}{l}\text { ULE MASS } \\
\text { lat te ed } \\
\text { (ronoigotopic) }\end{array}$} & \multicolumn{2}{|c|}{ Error window: $\left[\begin{array}{l}-1.75,+1.75] \\
=\Rightarrow\end{array}\right.$} \\
\hline & & & Position & Amino acid sequence \\
\hline & & & $\begin{array}{l}4-32 \\
5-33\end{array}$ & (F) CFEPPY \\
\hline
\end{tabular}

PROTONATED PEPTIDE MOLECULE MASS

\begin{tabular}{|c|c|c|c|c|}
\hline & & & $=$ & $x_{1}$ \\
\hline & (monoisotopic) & & Position & Amino acid sequence \\
\hline 465.1 & 465.1768 & 465.5079 & $53-58$ & (R) TGGGA ( ) \\
\hline
\end{tabular}

Figure 5. Peptides detected in a chymotryptic digest of BPTI which were not among those predicted from the known action of the enzyme (Figure 3a) because of incomplete cleavage [average $[\mathrm{M}+\mathrm{H}]^{+} \mathrm{m} / \mathrm{z}$ 3497.4; the second of the three peptides found within the specified error window] or nonspecific cleavage at a nonchymotryptic site, the C-terminus of arginine [monoisotopic $[\mathrm{M}+\mathrm{H}]^{+} m / z$ 465.1]. The user may specify an error window above and below the $[\mathrm{M}+\mathrm{H}]^{+}$mass-to-charge ratio entered, otherwise COMPOST uses $\pm 0.05 \%$ of this value as error windows.

digest specified will include those linked by disulfides (Figure 3b).

Option 3 allows the user to specify an amino acid sequence (as long as 15 amino acids), and the program then locates all occurrences of this sequence in the longer amino acid sequence that was entered originally. For example, if the user types " $\mathbf{N} \# \mathbf{S}^{\prime \prime}$, the program will locate and list all three amino acid sub-
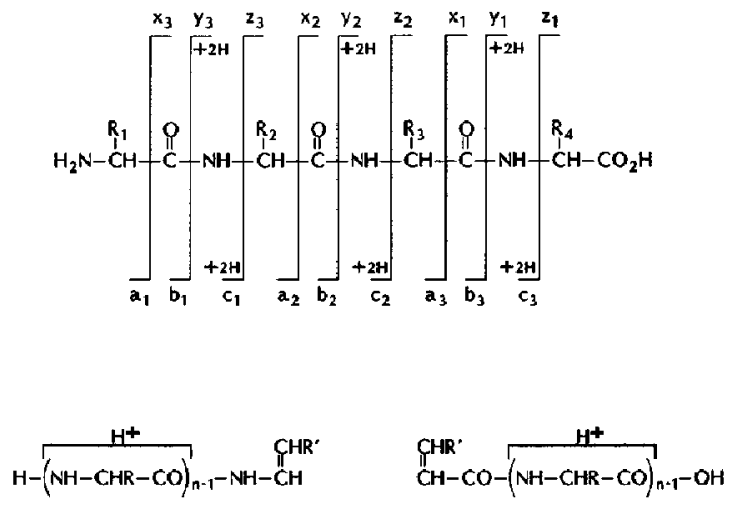

$d_{n}$ $w_{n}$

$$
\mathrm{HN}=\mathrm{CH}-\mathrm{CO}-\overbrace{(\mathrm{NH}-\mathrm{CHR}-\mathrm{CO})_{\mathrm{n}-1}-\mathrm{OH}}^{+}
$$

$v_{n}$

\section{$\mathrm{H}_{2} \stackrel{+}{\mathrm{N}}=\mathrm{CHR}$ \\ Immonium lon}

(denoted by single letter code)
$\mathrm{H}_{2} \mathrm{~N}-\mathrm{CHR}-\mathrm{CO}-\mathrm{NH}-\mathrm{CHR}-\mathrm{C} \equiv \stackrel{+}{\mathrm{O}}$

Internal Acyl Fragment lón

(denoted by single letter code)
Scheme I. High-energy CID fragments from linear peptides. $R^{\prime}$ (in $d_{n}$ and $w_{n}$ ions) is hydrogen or a substituent at the $\beta$-carbon (Ile. Thr, and Val); if there are two different substituents (Ile and Thr) they give rise to two $d$ and $w$ ions ( $d_{a}$ and $d_{b}$ and $w_{a}$ and $w_{b}$, respectively), as shown in Figure 6 .

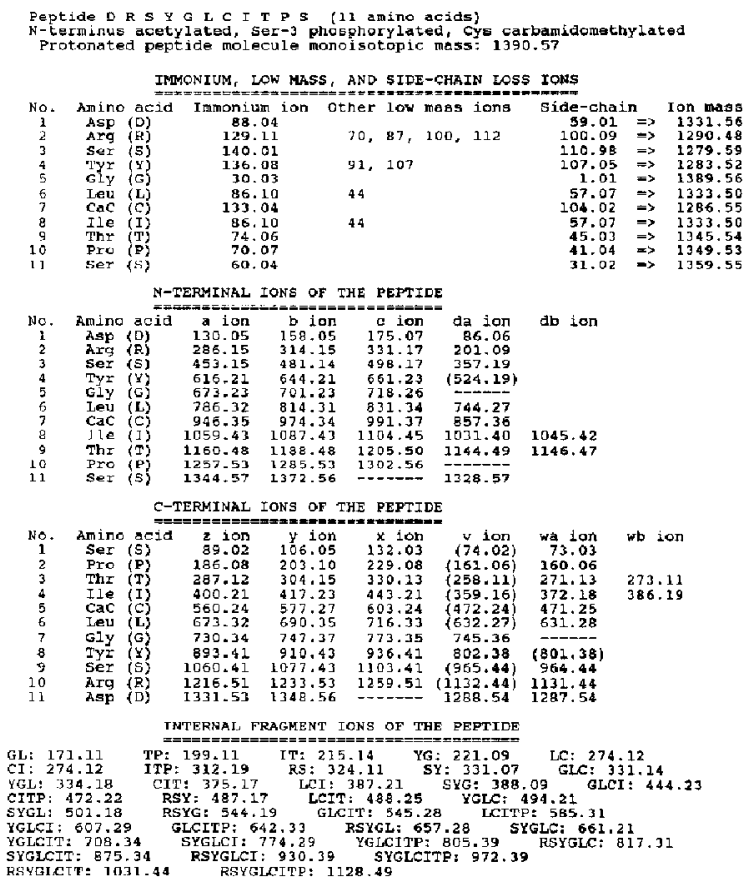

Figure 6. High energy CID fragment ions for the undecapeptide DRS YGLCITPS as calculated by COMPOST. The Nterminus is acetylated, the first serine (at position 3 ) phosphorylated, and the cysteine is carbamidomethylated. Mass values in parentheses are expected to be of low abundance or absent. For example, in the CID mass spectra with abundant N-terminal ions, the $\mathrm{d}_{\mathrm{n}}$ ions for aromatic amino acids are always much less abundant $(<20 \%)$ than the corresponding $a_{n}$ ions and are absent for $G$, A, and $P$. Similarly, in CID mass spectra with abundant $C$-terminal ions, the $w_{n}$ ions for aromatic amino acids are generally not formed, whereas $v_{n}$ ions may be of high abundance for such amino acids.

sequences consisting of asparagine, followed by any amino acid, followed by serine, which are potential $\mathrm{N}$-glycosylation sites. In Figure 4 the glycosylation sites for yeast external invertase [6] are displayed. Option 5 carries out similar operations but the results are displayed on the video terminal with appropriate highlighting.

Option 4 enables the user to search the sequence entered for amino acid subsequences of a specified mass. Sometimes, in the FAB mass spectra of enzymatic digests of proteins of known sequence, peptides are detected which are not among those expected based on the specificity of the enzyme used. This may be the result of nonspecific activity of the enzyme (e.g., trypsin often exhibits chymotryptic activity as well), or incomplete cleavage at certain sites. COMPOST finds all peptides (contiguous amino acid subsequences), the mass of which matches that determined experimentally and which could result, by random cleavage, from the sequence entered (Figure 5).

Finally, option 6 calculates the mass to charge ratio values of all possible fragments produced by high-en- 
ergy CID of a protonated peptide molecule [7]. $\mathrm{N}$ - and $\mathrm{C}$-terminal fragment ions, along with internal fragment, immonium, and side-chain loss ions (Scheme I) are generated. A typical output of this option is shown in Figure 6. This is useful for predicting the possible peaks of the CID mass spectrum of a known or hypothetical peptide or for assessing the correctness of a sequence deduced from the CID mass spectrum of a peptide of unknown structure.

The output from options 4, 6, and 7 can be saved in a file or printed. COMPOST runs on VAX computers or workstations under VMS version 5.3 (but should work with versions 4.0 and higher) in less than 0.5 Mbyte of memory at peak usage ${ }^{2}$ and requires a

\footnotetext{
${ }^{2}$ Because of the virtual memory access inherent in the VMS operating system, the program should run even with considerably lower memory allocation to the user without any perceptible difference in
} performance.
VT100 (or compatible) terminal, Copies of the program may be obtained by writing to the authors.

\section{Acknowledgments}

We would like to thank ]. E. Biller for helpful discussions. This work was supported in part by grants from the National Institutes of Health (RR00317 and GM05472).

\section{References}

1. Scoble, H.A.; Biller, J.E.; Biemann, K. Fresenius Z. Anal. Chem. 1987, 327, 239-245.

2. Johnson, R.S.; Biemann, K. Biomed. Environ. Mass Spectrom 1989, 18, 945-957.

3. Lee, T.D.; Vemuri, S. Biomed. Environ. Mass Spectrom. 1990 , 19, 639-645.

4. Wapstra, A.H.; Audi, G. Nucl. Phys. 1985, A432, 1-54.

5. Martin, R.L.; et al. Pure Appl. Chem, 1988, 60, 841-854.

6. Reddy, V.A.; Johnson, R. S.; Biemann, K.; Williams, R. S.; Ziegler, F. D.; Trimble, R. B.; Maley, F. J. Biul. Chem. 1988, 263, 6978-6985.

7. Biemann, K. Biomed. Environ. Mass Spectrom. 1988, 16 , 99-111. 